\title{
Outdoor stocking density in free-range laying hens: radio-frequency identification of impacts on range use
}

\author{
D. L. M. Campbell ${ }^{1,2 \dagger}$, G. N. Hinch ${ }^{1}$, T. R. Dyall ${ }^{2}$, L. Warin ${ }^{2,3}$, B. A. Little ${ }^{4}$ and C. Lee $e^{1,2}$ \\ ${ }^{1}$ School of Environmental and Rural Science, University of New England, Armidale, NSW 2351, Australia; ${ }^{2}$ Commonwealth Scientific and Industrial Research \\ Organisation, Agriculture, Armidale, NSW 2350, Australia; ${ }^{3}$ Department of Animal Science, AgroParisTech, 16 rue Claude Bernard, Paris 75005, France; \\ ${ }^{4}$ Commonwealth Scientific and Industrial Research Organisation, Agriculture, St Lucia, QLD 4067, Australia
}

(Received 11 January 2016; Accepted 20 May 2016; First published online 22 June 2016)

\begin{abstract}
The number and size of free-range laying hen (Gallus gallus domesticus) production systems are increasing within Australia in response to consumer demand for perceived improvement in hen welfare. However, variation in outdoor stocking density has generated consumer dissatisfaction leading to the development of a national information standard on free-range egg labelling by the Australian Consumer Affairs Ministers. The current Australian Model Code of Practice for Domestic Poultry states a guideline of 1500 hens/ha, but no maximum density is set. Radio-frequency identification (RFID) tracking technology was used to measure daily range usage by individual ISA Brown hens housed in six small flocks (150 hens/flock - 50\% of hens tagged), each with access to one of three outdoor stocking density treatments (two replicates per treatment: 2000, 10000, 20000 hens/ha), from 22 to 26, 27 to 31 and 32 to 36 weeks of age. There was some variation in range usage across the sampling periods and by weeks 32 to 36 individual hens from the lowest stocking density on average used the range for longer each day $(\mathrm{P}<0.001)$, with fewer visits and longer maximum durations per visit $(\mathrm{P}<0.001)$. Individual hens within all stocking densities varied in the percentage of days they accessed the range with $2 \%$ of tagged hens in each treatment never venturing outdoors and a large proportion that accessed the range daily (2000 hens/ha: 80.5\%; 10000 hens/ha: 66.5\%; 20000 hens/ha: $71.4 \%)$. On average, $38 \%$ to $48 \%$ of hens were seen on the range simultaneously and used all available areas of all ranges. These results of experimental-sized flocks have implications for determining optimal outdoor stocking densities for commercial free-range laying hens but further research would be needed to determine the effects of increased range usage on hen welfare.
\end{abstract}

Keywords: laying hen, free-range, stocking density, radio-frequency identification, behaviour

\section{Implications}

Free-range production systems vary in the amount of outdoor space provided per individual hen but few studies have assessed the impacts on range use. Radio-frequency identification (RFID) tracking of hens from ages 22 to 36 weeks showed individuals with more outdoor space per bird (2000 hens/ha), used the range area for longer than hens housed at 10000 or 20000 hens/ha. During weeks 27 to 36 , hens within the highest stocking density spent the least time outdoors. Outdoor stocking density affected range use which has implications for free-range system management and developing legislative standards that optimise hen welfare.

\section{Introduction}

Consumer concern for animal welfare is driving changes in the laying hen (Gallus gallus domesticus) industry both within

\footnotetext{
${ }^{\dagger}$ E-mail: danaleigh.m.campbell@gmail.com
}

Australia and globally leading to growth in alternative housing to the conventional cage such as free-range production systems which are viewed as more natural and ethical (Schröder and McEachern, 2004). Free-range systems provide hens with the choice between indoor and outdoor areas and, thus, the opportunity to access fresh air, variable weather and exhibit behaviour such as foraging, sun bathing and eating insects (Fanatico, 2006; Knierim, 2006). Within Australia, free-range eggs are growing in popularity (Rault et al., 2013), but considerable variation in current housing parameters, including outdoor stocking density, has sparked consumer dissatisfaction and public debate (Consumer Affairs Australia and New Zealand, 2015). The current Australian Model Code of Practice for the Welfare of Animals - Domestic Poultry (Primary Industries Standing Committee, 2002) states a density of 1500 hens/ha outdoors (at maximum occupancy) with higher hen densities requiring regular range rotation and no maximum density is stated. Thus, free-range systems within Australia currently span from a few hundred hens per hectare to several thousand hens per hectare. Subsequently, 
the Australian Consumer Affairs Ministers released a new free-range egg labelling information standard on 31 March 2016 requiring hens to have 'meaningful and regular access to the outdoors, with outdoor stocking of no more than one hen per square metre (maximum 10000 hens/ha)'. In addition to the national information standard on egg labelling, the Australian Egg Corporation Limited will be releasing new Australian Poultry Standards and Guidelines during 2016. However, there are currently a lack of scientific data available from both Australian and international free-range systems on impacts of outdoor range stocking density on hen range-use behaviour (Pettersson et al., 2016), thus negating objective determination of optimal outdoor space requirements for free-range laying hens.

The free-range system is a dynamic environment where hens have a daily choice of whether to access the outdoor resource. Therefore, to determine the preferred space requirements outdoors, it is imperative to measure how frequently individual hens choose to access the range. Previous studies using grouplevel live counts across commercial free-range farms within the UK, with flock sizes encompassing 100 to 16000 individuals housed at indoor stocking densities from 4 to $12 \mathrm{birds} / \mathrm{m}^{2}$, showed on average, $12 \%$ of the flock was seen on the range simultaneously, with fewer birds ranging as flock size and indoor stocking density increased (outdoor stocking density not stated; Gilani et al., 2014). This inverse relationship between range use and/or indoor stocking density and flock size has been further supported by group-level direct observational studies within the UK and EU with similar low percentages of birds seen on the range simultaneously (e.g. Bubier and Bradshaw, 1998; Harlander-Matauschek et al., 2001; Hegelund et al., 2005).

To document individual-level patterns of outdoor access, researchers have employed the use of RFID technology to track range use of individual microchip-tagged hens (e.g. Richards et al., 2011; Gebhardt-Henrich et al., 2014). Recent research in European commercial systems incorporating a covered veranda and a free-range area, compared flocks sizes of $\sim 2000$ to $\geqslant 9000$ hens housed at an outdoor stocking density of 4000 hens/ha and showed $47 \%$ to $90 \%$ of tagged birds (5\% to $10 \%$ of total flock) visited the freerange area at least once (Gebhardt-Henrich et al., 2014). Similar to previous group-level observations, birds from smaller or medium-sized flocks visited the range more often and spent a longer time ranging, but many birds did not use the range every day (Gebhardt-Henrich et al., 2014). Richards and colleagues also evaluated individual range usage across the flock cycle in commercial laying hens within the UK with an outdoor stocking density of 1000 birds/ha (Richards et al., 2011). Approximately $80 \%$ of tagged birds $(10 \%$ of flock; 1500 hens/flock) were registered as using the pop holes frequently, $\sim 8 \%$ accessed the range on $<10 \%$ of available days and a similar proportion were never registered on the RFID system at all (Richards et al., 2011). Finally, previous studies in the same experimental facility as the current research showed $39 \%$ of hens in flock sizes of 300 birds at an outdoor stocking density of 2400 hens/ha used the range on a daily basis, with $13 \%$ never venturing outdoors (Hinch and Lee, 2014).

RFID tracking with varying flock sizes and range area is consistently showing that not all hens choose to visit the range area daily, with some hens never venturing outside at all, including a wide variation in daily time spent outside. The objective of this experiment was to use RFID tracking of individual hens in an experimental free-range system to measure the impact of three different outdoor range stocking densities (2000, 10000 and 20000 hens/ha) on average daily time spent outside, average number of daily visits outside, maximum visit durations and percentage of available ranging days that individual hens ventured outside, including video decoding of total numbers of hens outside and present in different areas of the range across the day.

\section{Material and methods}

\section{Animals and housing}

In total, 900 ISA Brown pullet laying hens (Gallus gallus domesticus) were placed at 16 weeks of age (May 2015) into the University of New England's Laureldale experimental free-range facility located in Armidale, Australia. Floor-raised pullets were obtained from a commercial supplier. Birds were IR beak-trimmed at 1-day old with a hot-blade re-trim at 11 weeks of age.

The hens were evenly distributed between six indoor floor pens ( 150 birds/pen) with equal indoor stocking densities of $9 \mathrm{birds} / \mathrm{m}^{2}$ (Figure 1). Indoor resources per bird were provided to meet or exceed the Australian Model Code of Practice for the Welfare of Animals - Domestic Poultry (Primary Industries Standing Committee, 2002) (Figure 1). Birds were fed a commercial layer mash (Barastoc - Premium Top Layer Mash, Melbourne, VIC, Australia) available ad libitum. Rice hulls at an initial depth of $\sim 4 \mathrm{~cm}$ were provided as a litter substrate.

The shed was fan-ventilated but not temperature or humidity controlled with an average indoor temperature of $8.8^{\circ} \mathrm{C} \pm 4.09$ (range: $-2.2^{\circ} \mathrm{C}$ to $19.4^{\circ} \mathrm{C}$ ) across the trial period, as measured at bird height. Incandescent lighting gradually increased from 15 to $16 \mathrm{~h}$ of light by 20 weeks of age (lights on at $0400 \mathrm{~h}$, lights off at $2000 \mathrm{~h}$ ). The lux (Lutron Light Meter, LX-112850; Lutron Electronic Enterprise CO., Ltd, Taipei, Taiwan) inside the pen when the pop holes were closed, measured at bird height in three locations within the pen (front, middle and back), ranged from 4 to 21 lux. This range increased to 5 to 190 lux when the pop holes were open as measured on one cloudy and one sunny day.

Each indoor pen was associated with a designated fenced ( $2 \mathrm{~m}$ high to prevent birds flying over but birds were not visually isolated between ranges) outdoor area which was initially $100 \%$ covered (before bird access) with a variety of grass and weeds typical to the region. To minimise the variables associated with birds accessing the outdoor areas, no shade or shelter structures that have been shown to encourage range use were present (Hegelund et al., 2005; 


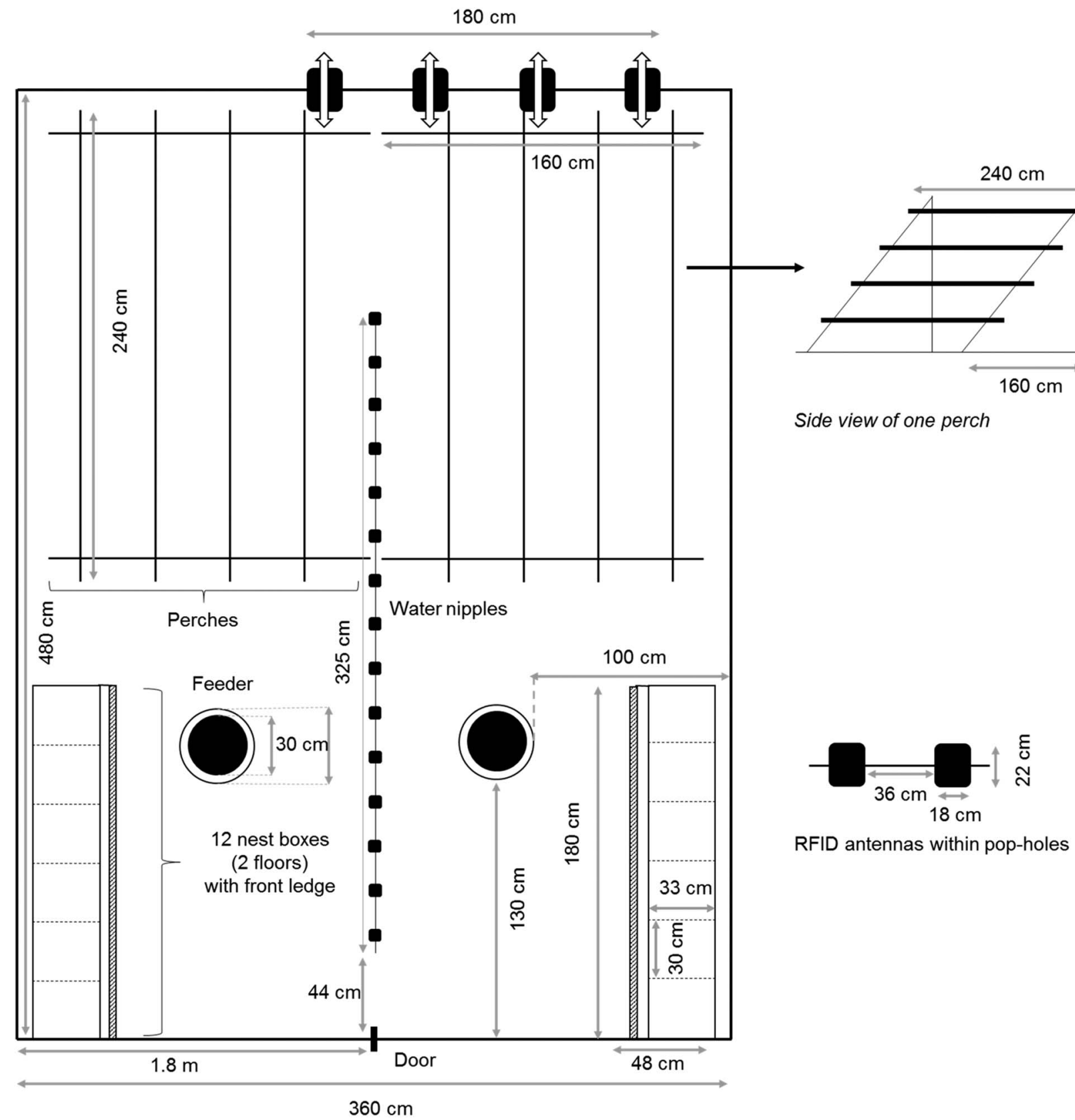

Figure $1 \mathrm{~A}$ top-down schematic of the hens' indoor pen set-up showing location of the range pop holes (including radio-frequency identification (RFID) antennas), perches (side view included), nest boxes, feed and water. Each indoor pen had identical resources and configuration.

Nagle and Glatz, 2012). The impact of three outdoor stocking density treatments were assessed with two replicates per treatment (maximum replicates able to fit within the experimental range area) (Figure 2). The pop holes containing four RFID passageways (Figure 1) that provided range access were first opened at 21 weeks of age $(\sim 20 \%$ production) with subsequent daily access from 0900 to $1630 \mathrm{~h}$ across 15 weeks over winter. Birds were not forced onto the range as measuring natural range usage (per commercial practice) was the objective of this research. Assessing outdoor access over the winter period provided ideal conditions for frequent range usage as days were typically dry (sunny/cloudy with rain on $12 \%$ and snow on $2 \%$ of days) and outdoor temperatures generally mild (average outdoor temperatures during range access hours were $14.3^{\circ} \mathrm{C} \pm 5.34$; range: $-3.5^{\circ} \mathrm{C}$ to $27.9^{\circ} \mathrm{C}$. Photos of each range were taken weekly to document hen degradation of ground cover with visual estimations made each week on percentage of ground cover remaining (green $v$. brown area). Hens were encouraged to return inside each afternoon using $350 \mathrm{~g}$ of poultry grain mix per pen (Barastoc - Poultry Grain Mix, Melbourne, VIC, Australia) and all birds were held inside each night.

\section{Radio-frequency identification tracking}

All birds were leg-banded (plastic numbered split-ring; Roxan Developments Ltd, Selkirk, Scotland) at 17 weeks of age with 75 randomly selected birds in each pen (50\%) also fitted with 


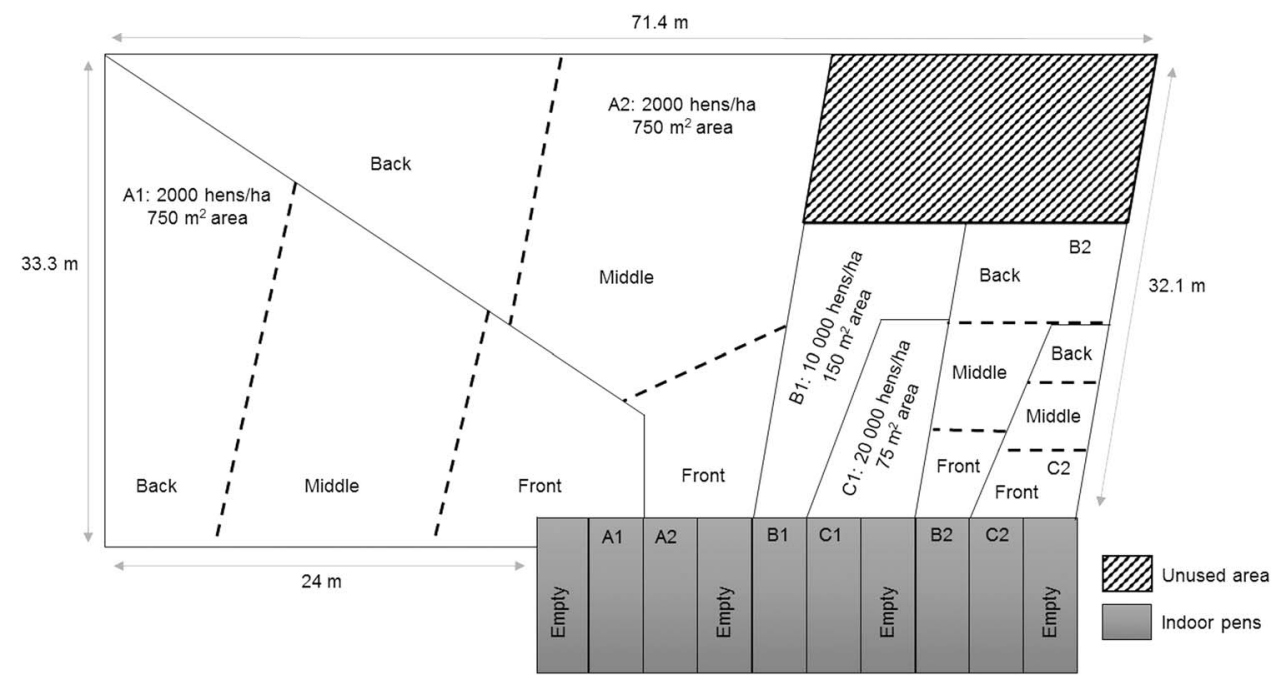

Figure $2 \mathrm{~A}$ map of the six indoor pens and their designated outdoor range areas for the three outdoor stocking density treatments $(2000,10000$, 20000 hens/ha), including the front, middle and back range delimitations used for describing range area usage by all hens (range delimitations were equal between both ' $B$ ' and both ' $C$ ' pens, respectively).

an adjustable leg band (Roxan Developments Ltd) containing a glued RFID microchip (Trovan ${ }^{\circledR}$ Unique ID 100 (FDX-A): operating frequency $128 \mathrm{kHz}$; Microchips Australia Pty Ltd, Keysborough, VIC, Australia). All microchips within leg bands were tested before being fitted to hens, and all microchips that were never registered on the system during the trial were re-tested to confirm their functionality. Three RFID systems were purchased from Microchips Australia Pty Ltd with equipment developed and built by Dorset Identification B.V. (Aalten, The Netherlands) using $\operatorname{Trovan}^{\circledR}$ technology. Each RFID system consisted of four passageways $(36 \mathrm{~cm} \mathrm{H} \times 18 \mathrm{~cm} \mathrm{~W}$ ) situated within the pop holes (Figure 1), each with paired optical beam sensors at either side of an RFID antenna plate and all connected to an RFID decoder downloading directly to a USB flash drive. Each passageway registered and recorded the date and time each tagged bird passed through and in which direction (onto the range, or into the pen) with a precision of $0.024 \mathrm{~s}$ (maximum detection velocity $9.3 \mathrm{~m} / \mathrm{s}$ ). These passageways were situated at a height ranging from 17 to $23 \mathrm{~cm}$ inside the pens and at heights ranging from 33 to $42 \mathrm{~cm}$ outside the pens depending on litter build-up depth inside or ground topography outside (as measured at 24 weeks). The RFID system used was previously configured in this experimental setting with width of pop hole passageways designed to allow one bird to pass through, and height above ground to encourage the bird to land onto the antenna with both feet (Hinch and Lee, 2014). Previous video validation showed $100 \%$ detection rate, but the system also registered 'false' readings such as a bird jumping onto the antenna and jumping back off, triggering only one set of sensor beams (Hinch and Lee, 2014). These false readings were filtered out with custom-designed software (see 'Data and statistical analyses'). The RFID systems were placed in the indoor pens 2 weeks before pop holes first opened and RFID tracking occurred daily from 22 to 36 weeks (1 week permitted to acclimate to the pop hole passageways and the range). However, due to having three
RFID systems only, one replicate from each stocking density was recorded for 2 weeks, then the three RFID units were swapped to record the second replicate for 2 weeks. In total (excluding days of system failure), daily tracking data were recorded for each stocking density as follows: 2000 hens/ha: 91 days; 10000 hens/ha: 91 days; 20000 hens/ha: 88 days.

\section{Range video recordings and decoding}

A series of hand-held video cameras (Panasonic HC-V110, Panasonic HDC-SD40 (Panasonic Australia Pty Ltd); Sony HDRXR260E, Sony HDR-XR550 (Sony Electronics Inc., San Diego, CA, USA)) were used to record each range between 26 and 28 weeks (peak production period) with 7 sampling days per range (with the equipment available, only three ranges could be recorded on 1 day, one range from each treatment replicate). On each sampling day, the entire range was video recorded from $0900 \mathrm{~h}$ (pop hole opening) to $1630 \mathrm{~h}$ (pop hole closing). Resulting videos were used to count the total number of birds outside in three different parts of the range (Figure 2): one close to the pop holes (front), one in the middle (middle) and one at the back of the range (back). Sampling occurred $10 \mathrm{~min}$ after pop hole opening, and every $20 \mathrm{~min}$ thereafter until pop hole closing (three observers decoded videos, inter-observer reliability 93\%). These range delimitations were designed to describe how the hens used the available outdoor area between different-sized ranges, but due to the size variation between and within pens, it was not possible to make any statistical comparisons between the areas.

\section{Ethical statement}

All research was approved by the University of New England Animal Ethics Committee (AEC14-100) before the start of data collection.

\section{Data and statistical analyses}

Discounting any data from birds that died part way through the trial, the individual hen sample sizes for daily RFID 
tracking data were as follows: 2000 hens/ha: $n=148$; 10000 hens/ha: $n=149 ; 20000$ hens/ha: $n=150$. RFID data were separated into individual hens' daily range use from weeks 22 to 26, weeks 27 to 31 and weeks 32 to 36 . These periods incorporated $\sim 2$ weeks of RFID tracking from each replicate within the three stocking densities. Although individual range use may be affected by activities of the group, space requirements are typically stated per bird, and it was the variation at the individual level within the group environment that was the focus for this study. All RFID data were run through a custom-built software program written in the 'Delphi' language that filtered out any unpaired false readings, such as if a bird sat in the pop hole and triggered continuous readings, or jumped into the pop hole but never completed a full transition either onto the range or back into the pen. The program then summarised the daily data per hen from within the three sampling time blocks across the experimental period to provide the daily time spent outdoors, the number of daily visits, maximum time per visit, and overall, how many days the range was accessed by each tagged hen (converted to percentage of total available days that each hen visited the range).

The daily time outdoors, and maximum time per visit were $\log _{10}$ transformed to normality with number of daily visits square-root transformed. Data were analysed in JMP 12.1.0 (SAS Institute Inc., Cary, NC, USA) using GLM with $\alpha$ set at 0.05 . GLMs were first used to compare the changes in rangeuse parameters between the three sampling week periods by all stocking densities combined. GLMs were then used to compare the effects of individual hens nested within pen replicate nested within stocking density, pen replicate nested within stocking density and stocking density on range-use parameters (daily hours outside, daily visits, maximum time per visit), separately within each sampling time period (weeks 22 to 26, weeks 27 to 31 and weeks 32 to 36 ). The main effects were still present when the interaction term of 'sampling weeks' was fitted to the model. We chose to analyse the sampling periods separately to focus on the differences between stocking density treatments within specific time periods as per the main objective of the study. Where significant differences were present between stocking densities, Student's $t$ tests were applied to the least squares means with a Bonferroni correction applied to the $\alpha$ level to account for multiple post-hoc comparisons. The percentages of available days that hens accessed the range could not be transformed to normality, thus, non-parametric KruskalWallis tests were used to compare percentages of days outside between stocking densities separately for each sampling week period, and to compare all stocking densities combined across sampling weeks. Post-hoc comparisons for significant effects were made using the Bonferroni-Dunn method. Spearman's $\rho$ for non-parametric data were used to compare the relationship between average daily hours spent outdoors and total percentage of available days the range was accessed across the entire trial period, separately for each stocking density (excluding those birds that never went outside).
Total hen counts per day from the video decoding were converted to percentages of birds on the range simultaneously. These percentages were then averaged across all sampling times of day to provide average daily values for 26,27 and 28 weeks of age for each stocking density. A GLM with repeated measures was used to compare the effect of sampling week and stocking density on the average percentage of hens out on the range. Where significant differences were present between stocking densities, Student's $t$ tests were applied to the least squares means with a Bonferroni correction applied to the $\alpha$ level to account for multiple post-hoc comparisons. Data from video decoding were also compiled graphically (only) to show the average percentages of hens out on the range within the three different range divides (front, middle, back) at each hour across the day, averaged across all sampling weeks, separately for each stocking density.

\section{Results}

All birds were in good visible health throughout the trial with flock-level mortality at $1 \%$, no instances of feather loss (bar one bird with head feather loss at trial conclusion) and only five birds ( $n=3$ RFID tagged, $n=2$ untagged) showed signs of footpad dermatitis.

\section{Ground cover}

Weekly photos taken of the range showed ground cover decreased from $100 \%$ to $0 \%$ coverage within 5 weeks in the 20000 hens/ha ranges, within 6 weeks in the 10000 hens/ha ranges, and only dropped as low at $20 \%$ in the 2000 hens/ha ranges by 8 weeks. Data collection occurred over the winter period where minimal pasture growth would be expected.

\section{Range use}

RFID tracking. Within all stocking densities combined, hours spent outdoors increased across trial duration $(P<0.001$, weeks 22 to 26 : raw values mean $3.44 \pm$ SE 0.03 ; weeks 27 to 31: $4.01 \pm 0.03$; weeks 32 to $36: 4.20 \pm 0.03$, Figure 3). Within each sample period, there were differences in the daily hours outdoors between individual hens within each replicate of each stocking density treatment $(P<0.001)$ and differences between replicates within stocking densities $(P<0.001)$.These differences in replicates might be expected given ranging changed across time and replicates were assessed separately. There were also differences between stocking densities with hens in the 2000 hens/ha density treatment spending more time outside than hens from both the 10000 hens/ha and 20000 hens/ha densities during weeks 22 to 26 ( $P<0.001$, Figure 3$)$. Within weeks 27 to 31 and weeks 32 to 36 , hens from the 2000 hens/ha density spent the most time outdoors and hens from the 20000 hens/ha density spent the least $(P<0.001$, Figure 3$)$.

Across all stocking densities combined, the number of daily visits outdoors differed between sample weeks with the fewest visits during weeks 22 to 26 and the most visits during weeks 32 to $26(P<0.001$, weeks 22 to 26 : raw values mean $11.39 \pm$ SE 0.10 ; weeks 27 to $31: 12.30 \pm 0.10$; 


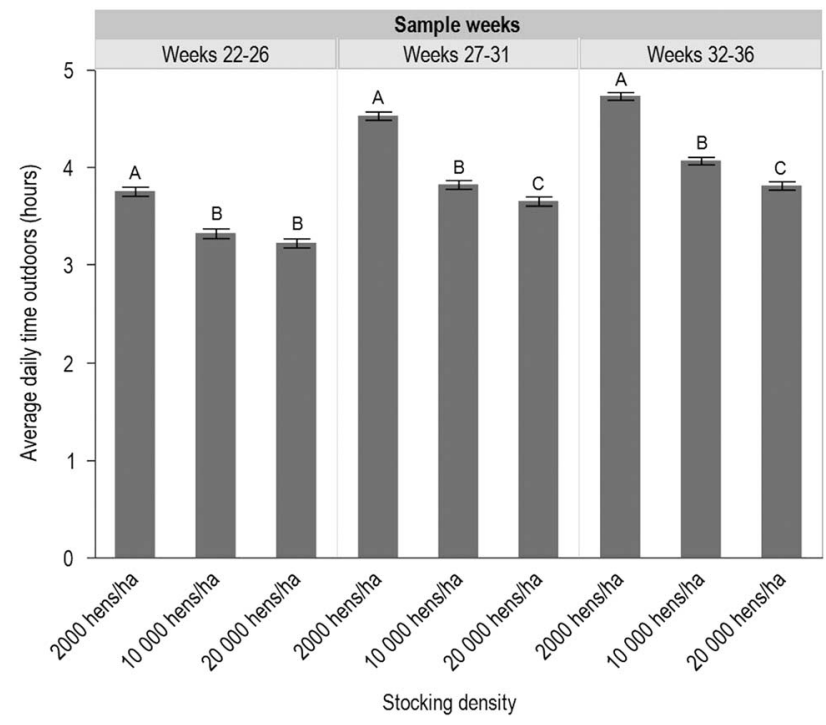

Figure 3 The average time (hours) \pm SE (of the raw values) spent outdoors per day for hens from the three stocking density treatments $(2000,10000,20000$ hens/ha) within the three sample periods (weeks 22 to 26 , weeks 27 to 31 and weeks 32 to 36 ). Dissimilar letters indicate differences between stocking densities within sample weeks.

weeks 32 to $36: 13.91 \pm 0.10$, Figure 4). Within each sample period, there were differences in the number of daily visits between individual hens within each replicate of each stocking density treatment $(P<0.001)$ and differences between replicates within stocking densities $(P<0.001)$. There were also differences between stocking densities, with hens in the 2000 hens/ha density showing the most visits outdoors during weeks 22 to 26 ( $P<0.001$, Figure 4$)$. Within weeks 27 to 31 , hens in the 2000 hens/ha densities showed the fewest visits outdoors $(P<0.001$, Figure 4). During weeks 32 to 36 hens from the 2000 hens/ha density showed the fewest visits outdoors and hens from the 20000 hens/ha density the most $(P<0.001$, Figure 4).

Across all stocking densities combined, the maximum time (minutes) per visit did not differ between sample weeks $(P=0.29$, Figure 5$)$. Within each sample period, there were differences in the maximum time per visit between individual hens within each replicate of each stocking density treatment $(P<0.001)$ and differences between replicates within stocking densities $(P<0.001)$. There were also differences between stocking densities with hens in the 10000 hens/ha density showing longer maximum times per visit than hens from the 2000 hens/ha density during weeks 22 to 26 , but neither density group differed from the 20000 hens/ha density $(P<0.03$, Figure 5$)$. Within weeks 27 to 31 , hens from the 2000 hens/ha density spent the longest time per visit outdoors $(P<0.001)$ and within weeks 32 to 36 , hens from the 2000 hens/ha density spent the longest time per visit outdoors and hens from the 20000 hens/ha stocking density treatment spent the shortest $(P<0.001$, Figure 5$)$.

Within all stocking density treatments within all sampling periods the individual hens varied in the percentage of total available days they accessed the range (Figure 6), but there

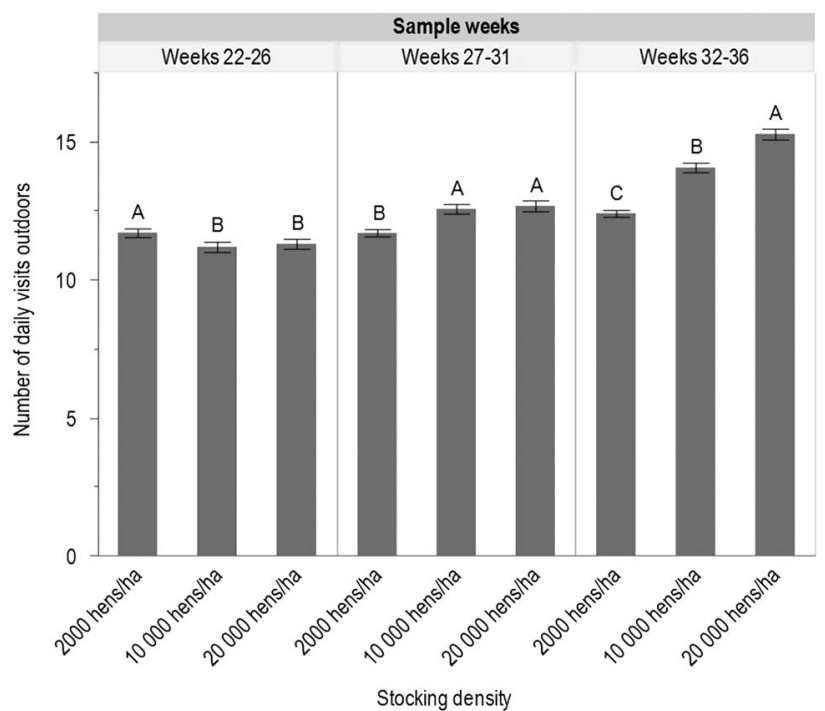

Figure 4 The average number \pm SE (of the raw values) of daily visits outdoors by hens from the three stocking density treatments $(2000$, 10000,20000 hens/ha) within the three sample periods (weeks 22 to 26 , weeks 27 to 31 and weeks 32 to 36 ). Dissimilar letters indicate differences between stocking densities within sample weeks.

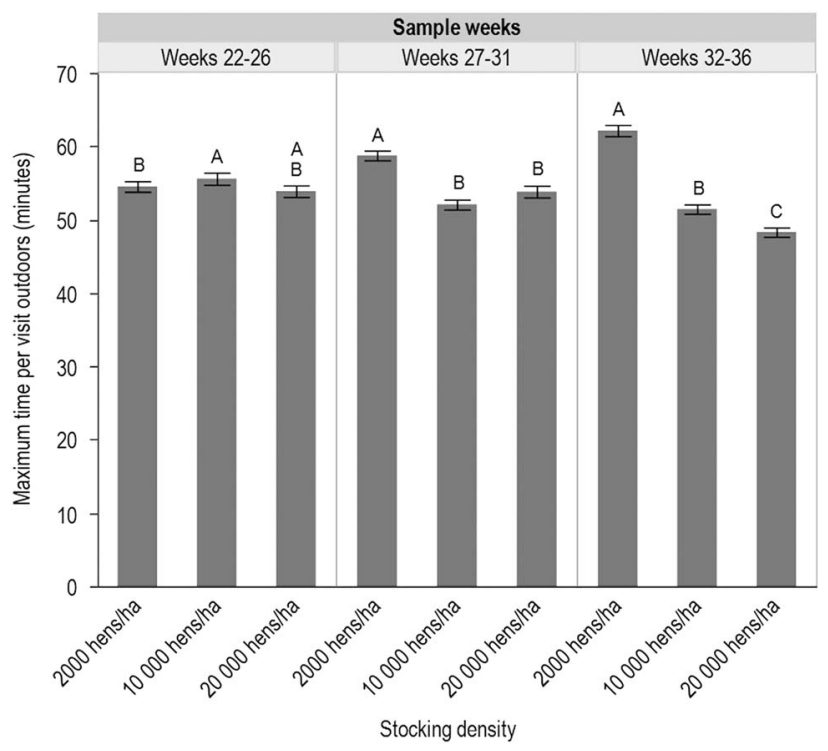

Figure 5 The average maximum time (minutes) \pm SE (of the raw values) spent outdoors per visit for hens from the three stocking density treatments $(2000,10000,20000$ hens/ha) within the three sample periods (weeks 22 to 26 , weeks 27 to 31 and weeks 32 to 36 ). Dissimilar letters indicate differences between stocking densities within sample weeks.

were no differences between stocking densities within each sampling period in the percentage of available days that individual hens accessed the range (all $P \geqslant 0.14$, Figure 6). Across the trial duration, there was a very small percentage of hens from each density that never went outdoors (although most did trigger false readings on the RFID system indicating functional tags; all treatments: $2 \%$ of tagged hens) and a small percentage that visited the range on $1 \%$ to 


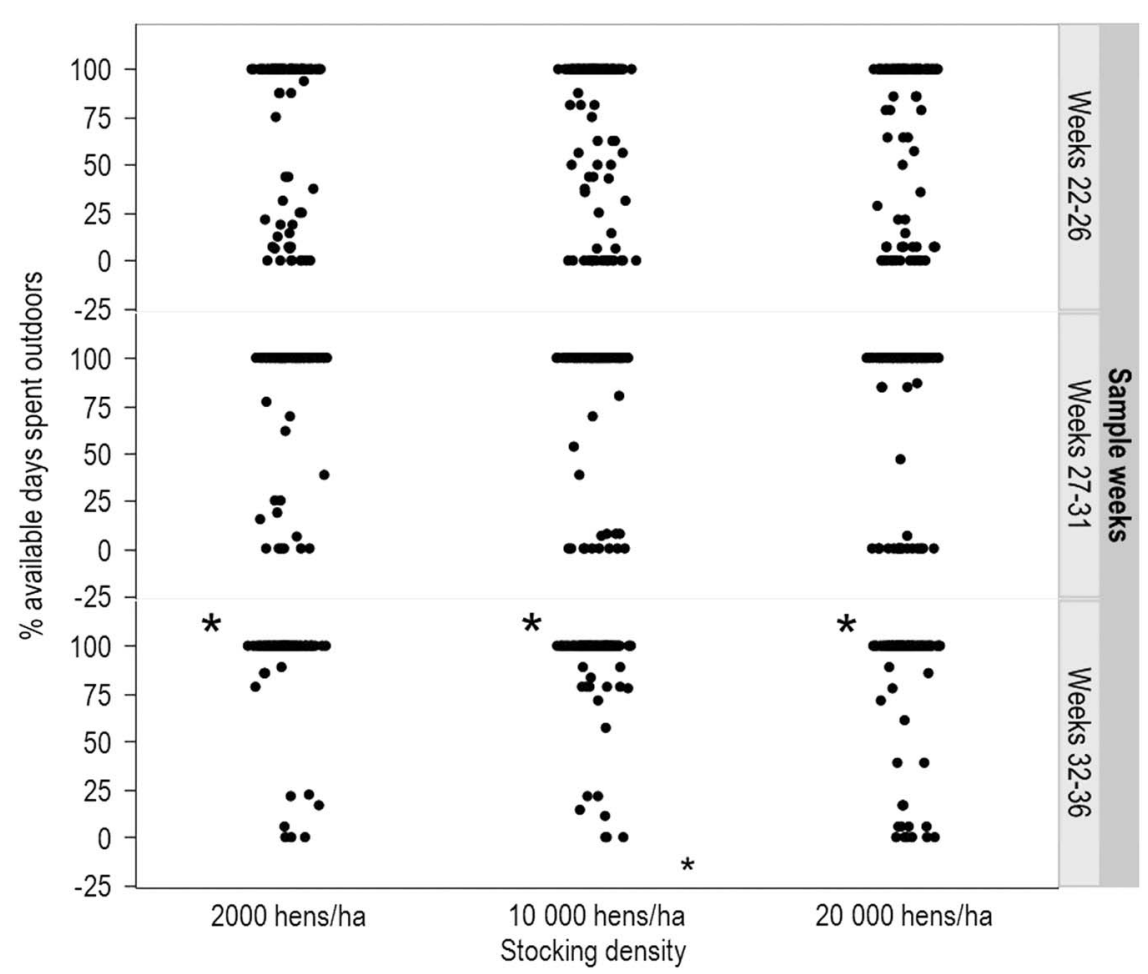

Figure 6 The percentage of available days that individual hens from each of the three stocking density treatments $(2000,10000,20000$ hens/ha) accessed the range within the three sample periods (weeks 22 to 26, weeks 27 to 31 and weeks 32 to 36) where differences between sampling weeks are indicated by '*'.

$10 \%$ of available days (2000 hens/ha: $1.3 \% ; 10000$ hens/ha: $1.3 \% ; 20000$ hens/ha: 6\%) (Figure 6). However, there were a large proportion of hens that visited the range on a daily basis across the entire trial period (2000 hens/ha: $80.5 \%$; 10000 hens/ha: $66.5 \% ; 20000$ hens/ha: 71.4\%; Figure 6). Within all stocking densities combined, there were differences across the sampling periods with more hens using the range during the final 32 to 36 weeks sampling period $(P<0.001$, Figure 6).

Finally, there were positive relationships within all stocking densities between average time spent outdoors and the percentage of available days the range was accessed (2000 hens/ha: $r_{s}=0.45, P<0.001 ; 10000$ hens/ha: $r_{s}=0.43$, $P<0.001 ; 20000$ hens/ha: $r_{s}=0.42, P<0.001$ ).

Video observations. Total counts of all hens on the range at 26 to 28 weeks showed the highest percentage of hens used the range in the 2000 hens/ha stocking density and the lowest percentage of birds in the 20000 hens/ha stocking density but neither of these densities differed from the 10000 hens/ha density treatment $(P<0.001,2000$ hens/ha: least squares mean (LSM) $48.87 \pm$ SE 1.72; 10000 hens/ha: $41.81 \pm 1.79,20000$ hens/ha: $36.88 \pm 1.76)$. On average, less than half of the birds were on the range at any point in time within each stocking density (range of all individual sampling counts 2000 hens/ha: $2.67 \%$ to $78 \% ; 10000$ hens/ ha: $10 \%$ to $74.67 \% ; 20000$ hens/ha: $2.67 \%$ to $64 \%)$. There tended to be an effect of sampling week $(P=0.05)$ but no interaction between stocking density and sampling week
$(P=0.69)$. Hens within each stocking density used all areas of the range across all times of day (Figure 7).

\section{Discussion}

The RFID tracking of individual free-range laying hens housed with access to different-sized ranges that simulated three different outdoor stocking densities, showed a linear relationship between stocking density and range use through most of the trial. Hens housed in the lowest outdoor stocking density (2000 hens/ha), spent more time outdoors with fewer visits of longer maximum duration and hens housed at the highest stocking density spent less time outdoors with more visits of shorter duration. Within all stocking densities individual hens showed great variation in the percentage of days they accessed the range, including hens that never went outside and hens that used the range daily with on average, $<50 \%$ of birds on the range simultaneously.

The average daily time outdoors of $\sim 3$ to $5 \mathrm{~h}$ across all densities (see Figure 3 ) is comparable with other studies of hens in wintergardens (covered ranges) showing either 2 to $8 \mathrm{~h} /$ day (Thurner and Wendl, 2005) or on uncovered ranges showing between $3 \mathrm{~h} 25 \mathrm{~min}$ and $5 \mathrm{~h} 25 \mathrm{~min} /$ day outside (Thurner et al., 2010), although these times were highly dependent on weather and season. Hens in the lowest stocking density may have spent longer outdoors as they had the greatest amount of space available to them, not just on a per bird basis $\left(5 \mathrm{~m}^{2}\right)$, but a larger-sized area overall $\left(750 \mathrm{~m}^{2}\right.$ compared with 150 or $75 \mathrm{~m}^{2}$ ) and, thus, the furthest 


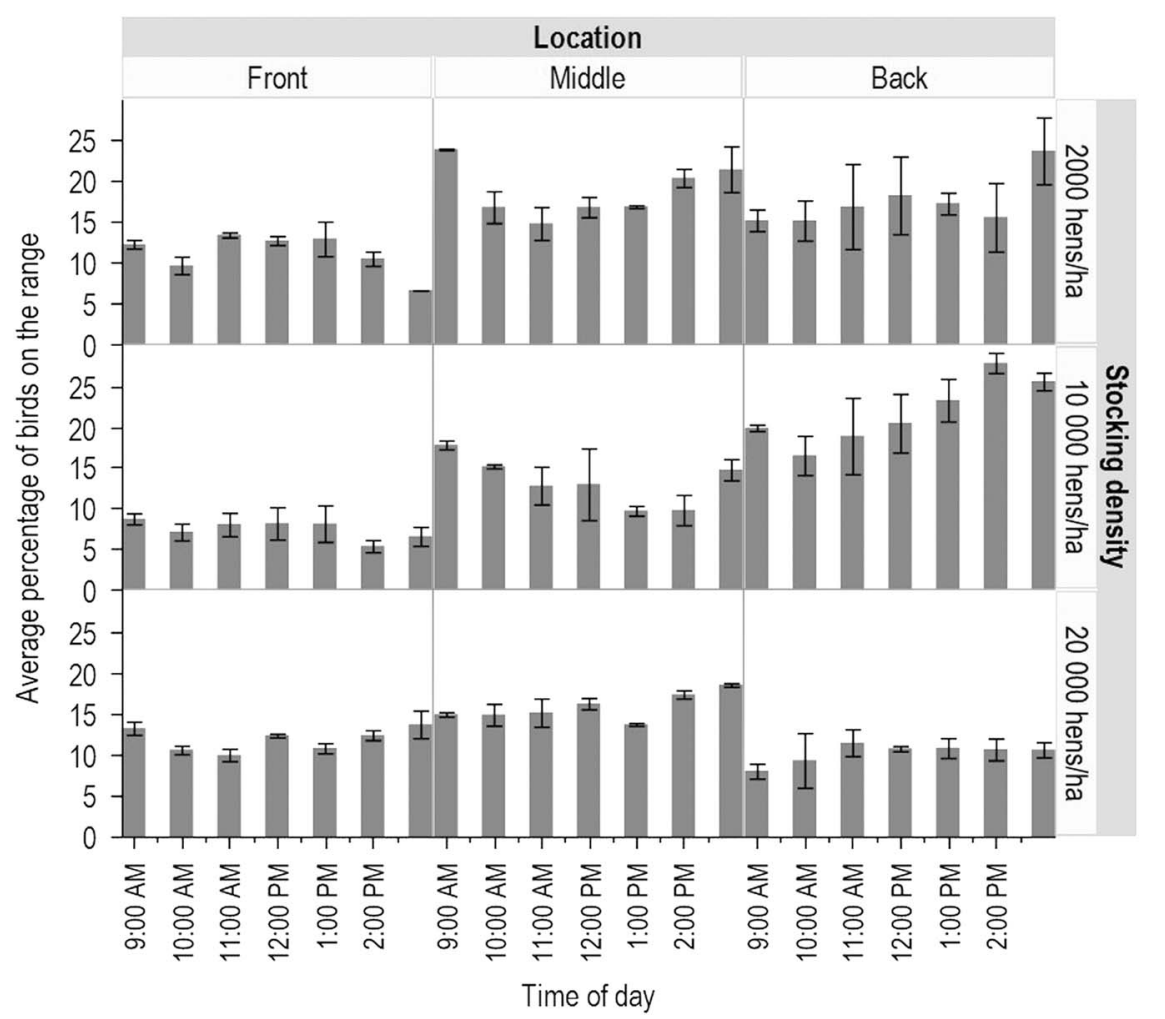

Figure 7 The average percentage $( \pm \mathrm{SE})$ of hens in different locations on the range (front, middle, back) for each stocking density treatment (2000, $10000,20000 \mathrm{hens} / \mathrm{ha}$ ) within each hour across the day from $0900 \mathrm{~h}$ until $1500 \mathrm{~h}$. See Figure 2 for map of range delimitations.

available distance to travel within their range. Video observations did show hens used all areas of their ranges, including visiting the back portion of the largest-sized ranges. This contrasts with previous group-level direct observations in commercial flocks that showed hens preferred to remain in the areas close to the pop holes with almost no hens visiting the furthest $40 \%$ of the range (varying-sized ranges observed, Hegelund et al., 2005). The smaller total area in the 20000 hens/ha stocking densities may account for the higher number of shorter-duration visits shown by hens using these ranges.

Hens in the lowest stocking density alternatively, may have spent more time outdoors as they had greater space in which to fulfill their ethological needs such as foraging/ scratching, walking, dust bathing and sun bathing. Kinematic analysis of space requirements of cage-housed hens showed a maximum average of $1913 \mathrm{~cm}^{2} /$ hen is needed to perform the behaviour of wing-flapping, the stationary behaviour considered to require the most space in comparison with, for example, standing or turning around (Mench and Blatchford, 2014). Another study looking at space requirements between small groups of hens concluded anything $<5000 \mathrm{~cm}^{2}$ (the space provided by the highest stocking density at $0.5 \mathrm{~m}^{2} /$ hen) imposed a restriction on free expression of behaviour by individual hens, such as walking or ground-pecking (Savory et al., 2006).These space requirements for the individual hen were either matched or exceeded by all the stocking density treatments in this study at hypothetical maximum capacity, suggesting sufficient space for free behavioural expression. However, similar to other studies (Thurner and Wendl, 2005; Gilani et al., 2014) on average, less than half of the hens in each pen were on the range simultaneously, highlighting the dynamic environment of the free-range system and how both indoor and outdoor stocking densities change throughout the day. Thus, a stocking density of 2000 hens/ha, with $5 \mathrm{~m}^{2}$ per individual bird at $100 \%$ range occupancy, is an underestimate of the actual space available to individual hens in this study that attracted them to use the range for longer periods and vice versa for the highest stocking density.

In addition to more space, the outdoor range provided resources not available indoors (sun, insects, grass, etc.) but food, water, perches, nest boxes and shelter were resources present indoors only, accompanied by less space available per hen, litter build-up, dimmer lighting and fan-ventilation, etc. Thus, it may be difficult to differentiate the attraction of the range itself, $v$. avoiding unappealing indoor conditions (Whay et al., 2007) and whether the choice between indoors and outdoors is dictated by different resources, available space, or different environmental conditions. In this study, all indoor conditions were kept equal with resources set to or exceeding the current model standards, but competition may have restricted resource access to some hens and, thus, they preferred to remain indoors to, for example, feed unrestrictedly as other birds moved outside. In addition, the motivation to fulfil certain behavioural needs may vary between individuals (Weeks and Nicol, 2006) thus increasing or reducing the attractiveness of varying resources provided 
by the free-range system (e.g. dust bathing outside in dirt; perch access indoors). Further studies could compare behaviours performed both indoors and outdoors by all hens to determine the value of the range in meeting ethological needs.

The longer time spent on the range in the lowest stocking density may have been partially related to the ground coverage as vegetation did not disappear completely as within the ranges of the other two densities. Previous observations in free-range systems showed hens spent more time walking and foraging on grass over gravel (Gebhardt-Henrich et al., 2014), of which foraging in red junglefowl will take up $60 \%$ of their daylight time budget (Dawkins, 1989). However, differences in range use between the 10000 hens/ha and 20000 hens/ha densities which both lost all vegetation indicate ground coverage is not the only factor influencing range usage. Current range stocking density requirements within the Australian Model Code of Practice for the Welfare of Animals - Domestic Poultry (Primary Industries Standing Committee, 2002) do stipulate range rotation is required as stocking densities increase over 1500 hens/ha. In this trial it was noted that as the ground cover depleted, the hens scratched out dust bathing pits in the dry dirt throughout all ranges. Further research could compare how behavioural time budgets of hens may change across the course of range ground-cover denudation.

Range usage increased across the observed lay period both in terms of hours spent outside, and the proportion of birds visiting the range on a daily basis. Differences between stocking densities also increased, suggesting further distinction between treatment groups may have been observed towards the end of the lay cycle or that different range-use patterns may be observed in different seasons (Pettersson et al., 2016). In addition, different strains of hens may vary in time spent outdoors and/or use of different range areas (Mahboub et al., 2004).

Determining the space requirements and optimal stocking densities of hens is intertwined with flock size and enclosure size. Several previous studies documented an inverse relationship between range use and flock size, in flocks ranging from a few hundred to several thousand hens (e.g. Bubier and Bradshaw, 1998; Harlander-Matauschek et al., 2001; Gebhardt-Henrich et al., 2014), even with equal stocking densities (Whay et al., 2007). Thus, we may expect that a group of 150 hens stocked at 20000 hens/ha would differ in range use from a group of 20000 hens on a hectare. Studies with broilers have looked to isolate the different effects of flock size, group size and density on space utilisation, showing that nearest-neighbour distances were constrained by density but broilers adapted to increasing enclosure size by using all available area with no effects of group size (Leone and Estevez, 2008; Leone et al., 2010). Larger flock size in laying hens has been shown to reduce aggression, possibly via hens abandoning hierarchical formations (Nicol et al., 1999) but as yet there are no data on the social effects of range use, whether individual hens access the range in the same groups and how this social facilitation and/or range space utilisation outdoors may be impacted by flock size. It is also possible that the use of all areas in the ranges in this study were influenced by other hens as barriers between ranges were transparent. In addition, there are few data on the impact of enclosure shape on range use and whether different range shapes as per this study, including placement of vertical fences may modulate ranging behaviour (Rault et al., 2013).

Overall, stocking density treatment impacted range usage with hens from the lowest stocking density (2000 hens/ha) accessing the range for longer each day and hens from the highest stocking density (20000 hens/ha) spending the least time outdoors. Range use varied across individual hens from all treatments with the majority of hens accessing the range daily, and a small percentage never venturing outdoors. This choice of environments, irrespective of whether birds go outdoors or remain indoors, may have a positive welfare impact on hens (Nicol et al., 2009). Further research should aim to correlate ranging with individual hen welfare parameters to determine whether there is a minimum amount of time a hen should spend outside and what the negative impacts (if any) of not ranging are, for optimal design of free-range environments that improve hen welfare.

\section{Acknowledgements}

This research was conducted within the Poultry CRC, grant 1.5.6, established and supported under the Australian Government's Cooperative Research Centres Program. L. Warin was supported by a Universities Federation for Animal Welfare Small Project and Travel Award. The authors thank Sue Belson, Jonathan Campbell, Grahame Chaffey, Mandy Choice, Andrew Cohen-Barnhouse, Bradley Dawson, Troy Kalinowski, Jim Lea, Barry Lockwood, Greg Mills, Dominic Niemeyer, Hélène Pecourt, Mark Porter, Samantha Robinson, Varun Uthappa and Lindsay Wittig for technical assistance and advice. Thank-you to anonymous reviewers for their comments that improved earlier versions of this manuscript.

\section{References}

Bubier NE and Bradshaw RH 1998. Movement of flocks of laying hens in and out of the hen house in four free range systems. British Poultry Science 39, S5-S18. Consumer Affairs Australia and New Zealand 2015. Free Range Egg Labelling, consultation paper. Retrieved on 11 December 2015 from http://www.treasury.gov. au/ /media/Treasury/Consultations\%20and\%20Reviews/Consultations/2015/ Free\%20range $\% 20$ egg $\% 20$ labelling/Key\%20Documents/PDF/free_range_egg_ labelling_RIS.ashx

Dawkins MS 1989. Time budgets in red junglefowl as a baseline for the assessment of welfare in domestic fowl. Applied Animal Behaviour Science 24, 77-80. Fanatico A 2006. Alternative poultry production systems and outdoor access. ATTRA Publication \#IP300. National Center for Appropriate Technology, Butte, Montana, USA.

Gebhardt-Henrich SG, Toscano MJ and Fröhlich EKF 2014. Use of outdoor ranges by laying hens in different sized flocks. Applied Animal Behaviour Science 155, 74-81.

Gilani AM, Knowles TG and Nicol CJ 2014. Factors affecting ranging behaviour in young and adult laying hens. British Poultry Science 55, 127-135.

Harlander-Matauschek A, Felsenstein K, Niebuhr K and Troxier J 2001. The effect of group size on locomotion of laying hens in outdoor runs. Proceedings of the 6th European Symposium on Poultry Welfare, 1-4 September, Zollikofen, Switzerland, pp. 330-331. 
Hegelund L, Sørensen JT, Kjaer JB and Kristensen IS 2005. Use of the range area in organic egg production systems: effect of climatic factors, flock size, age and artificial cover. British Poultry Science 46, 1-8.

Hinch $\mathrm{G}$ and Lee $\mathrm{C}$ 2014. New approaches to assess welfare in free range laying hens. Poultry CRC Ltd Final Report 1.5.2, Poultry CRC, Armidale, New South Wales, Australia.

Knierim U 2006. Animal welfare aspects of outdoor runs for laying hens: a review. NJAS - Wageningen Journal of Life Science 54, 133-145.

Leone EH, Christman MC, Douglass L and Estevez I 2010. Separating the impact of group size, density, and enclosure size on broiler movement and space use at a decreasing perimeter to area ratio. Behavioural Processes 83, 16-22.

Leone EH and Estevez I 2008. Use of space in the domestic fowl: separating the effects of enclosure size, group size and density. Animal Behaviour 76 1673-1682.

Mahboub HDH, Müller J and van Borell E 2004. Outdoor use, tonic immobility, heterophil/lymphocyte ratio and feather condition in free-range laying hens of different genotype. British Poultry Science 45, 738-744.

Mench JA and Blatchford RA 2014. Determination of space use by laying hens using kinematic analysis. Poultry Science 93, 794-798.

Nagle TAD and Glatz PC 2012. Free range hens use the range more when the outdoor environment is enriched. Asian-Australian Journal of Animal Science 25 584-591.

Nicol CJ, Caplen G, Edgar J and Browne WJ 2009. Associations between welfare indicators and environmental choice in laying hens. Animal Behaviour 78, 413-424.

Nicol CJ, Gregory NG, Knowles TG, Parkman ID and Wilkins L 1999. Differential effects of increased stocking density, mediated by increased flock size, on feather pecking and aggression in laying hens. Applied Animal Behaviour Science 65, 137-152.
Pettersson IC, Freire R and Nicol CJ 2016. Factors affecting ranging behaviour in commercial free-range hens. World's Poultry Science Journal 72, 137-149.

Primary Industries Standing Committee 2002. Model code of practice for the welfare of animals - domestic poultry, 4th edition. CSIRO Publishing, Collingwood, Victoria, Australia.

Rault JL, van de Wouw A and Hemsworth PH 2013. Fly the coop! Vertical structures influence the distribution and behaviour of laying hens in an outdoor range. Australian Veterinary Journal 91, 423-426.

Richards GJ, Wilkins LJ, Knowles TG, Booth F, Toscano MJ, Nicol CJ and Brown SN 2011. Continuous monitoring of pop hole usage by commercially housed free-range hens throughout the production cycle. The Veterinary Record 169, 338.

Savory CJ, Jack MC and Sandilands V 2006. Behavioural responses to different floor space allowances in small groups of laying hens. British Poultry Science 47, 120-124.

Schröder MJA and McEachern MG 2004. Consumer value conflicts surrounding ethical food purchase decisions: a focus on animal welfare. International Journal of Consumer Studies 28, 168-177.

Thurner S, Stefanie M, Wiebke I, Wendle G and Preisinger R 2010. Identification reliability of laying hens at the wide electronic pop hole. Landtechnik 65, 139-141.

Thurner S and Wendl G 2005. Individual ranging behaviour of laying hens automatic registration with RFID technology. Landtechnik 60, 0-31.

Weeks CA and Nicol CJ 2006. Behavioural needs, priorities and preferences of laying hens. World's Poultry Science Journal 62, 296-307.

Whay HR, Main DCJ, Green LE, Heaven G, Howell H, Morgan M, Pearson A and Webster AJF 2007. Assessment of the behaviour and welfare of laying hens on free-range units. Veterinary Record 161, 119-128. 